Article

\title{
Antimicrobial and Antibiofilm Activity against Staphylococcus aureus of Opuntia ficus-indica (L.) Mill. Cladode Polyphenolic Extracts
}

\author{
Federica Blando ${ }^{1}\left(\mathbb{D}\right.$, Rossella Russo $^{2}$, Carmine Negro ${ }^{3}$, Luigi De Bellis ${ }^{3}(\mathbb{D}$ \\ and Stefania Frassinetti ${ }^{2, *}$ \\ 1 Institute of Sciences of Food Production (ISPA), National Research Council (CNR), Research Unit of Lecce, \\ Via Prov. le Lecce-Monteroni, 73100 Lecce, Italy; federica.blando@ispa.cnr.it \\ 2 Institute of Biology and Agricultural Biotechnology (IBBA), National Research Council (CNR), Research Unit \\ of Pisa, Via Moruzzi 1, 56124 Pisa, Italy; rossella.wilbur@gmail.com \\ 3 Department of Biological and Environmental Sciences and Technologies (DiSTeBA), Salento University, \\ 73100 Lecce, Italy; carmine.negro@unisalento.it (C.N.); luigi.debellis@unisalento.it (L.D.B.) \\ * Correspondence: frassinetti@ibba.cnr.it; Tel.: +39-050-315-2704
}

Received: 26 March 2019; Accepted: 28 April 2019; Published: 2 May 2019

\begin{abstract}
Plant extracts are a rich source of natural compounds with antimicrobial properties, which are able to prevent, at some extent, the growth of foodborne pathogens. The aim of this study was to investigate the potential of polyphenolic extracts from cladodes of Opuntia ficus-indica (L.) Mill. to inhibit the growth of some enterobacteria and the biofilm formation by Staphylococcus aureus. Opuntia ficus-indica cladodes at two stages of development were analysed for total phenolic content and antioxidant activity by Oxygen Radical Absorbance Capacity (ORAC) and Trolox equivalent antioxidant capacity (TEAC) (in vitro assays) and by cellular antioxidant activity in red blood cells (CAA-RBC) (ex vivo assay). The Liquid Chromatography Time-of-Flight Mass Spectrometry (LC/MS-TOF) analysis of the polyphenolic extracts revealed high levels of piscidic acid, eucomic acid, isorhamnetin derivatives and rutin, particularly in the immature cladode extracts. Opuntia cladodes extracts showed a remarkable antioxidant activity (in vitro and ex vivo), a selective inhibition of the growth of Gram-positive bacteria, and an inhibition of Staphylococcus aureus biofilm formation. Our results suggest and confirm that Opuntia ficus-indica cladode extracts could be employed as functional food, due to the high polyphenolic content and antioxidant capacity, and used as natural additive for food process control and food safety.
\end{abstract}

Keywords: Opuntia ficus-indica cladode; flavonoid; antioxidant; antimicrobial activity; antibiofilm activity

\section{Introduction}

In recent years, there has been an increased interest in natural antimicrobials, especially those obtained from plants. Some plant species are a rich source of natural compounds with antimicrobial properties, which are able to prevent, at some extent, the growth of foodborne pathogens, and extend the shelf life of the food [1].

Pathogens involved in foodborne diseases or food processing plant contamination are often capable to adhere and form biofilms. These structures are organized communities of bacterial cells enclosed in a self-produced polymeric matrix, composed of polysaccharides, proteins and other organic components, adhering to inert or living surfaces [2]. It is known that bacteria within biofilms are more resistant to antibiotics and other chemical agents than planktonic cells in suspension and their increased tolerance towards antimicrobial agents reduces the effectiveness to the treatment of biofilm-related 
infections [3,4]. Bacterial biofilms spread widely and play important roles in many industrial activities. In the dairy industry or other food processing industries or food-contact surfaces, biofilm formation is a potential source of contamination and can lead to serious hygiene problems and economic losses [4].

Staphylococcus aureus is a well-known pathogen living as biofilm in a wide variety of environments and represents a severe risk of food contamination. It is has been found frequently on surfaces of food processing plants and it is responsible for infections related to consumption of fresh and processed foods [5].

Phenolic compounds occurring in vegetable foods and medicinal plants have been extensively investigated against a wide range of microorganisms. Several studies demonstrated the antimicrobial activity of dietary polyphenols, their activity on bacterial growth being mainly related to the strain, the polyphenol structure, and the dosage assayed [6-8]. Plant extracts, rich in polyphenols, has been reported to inhibit the biofilm formation by Staphylococcus aureus, including methicillin-resistant Staphylococcus aureus MRSA, Escherichia coli and Pseudomonas aeruginosa [9,10].

Opuntia ficus-indica (L.) Mill. (cactus pear) is a succulent species native from America, afterwards domesticated in other countries, occupying arid and semiarid zones. The first economic importance of Opuntia ficus-indica relies on the production of edible fruits, consumed fresh or transformed. Cladodes (succulent stem), known as pads or nopals, are also consumed at young stage in Mexico and United States in several different food preparation, or at older stage as forage, when there is shortage of fresh forage due to droughts [11,12].

The aims of this study were to investigate the potential of polyphenolic extracts from cladodes of Opuntia ficus-indica to inhibit the growth of some enterobacteria and the biofilm formation by Staphylococcus aureus. Moreover, cladode extracts were chemically and biochemically characterized, as high performance liquid chromatography time-of-flight mass spectrometry (HPLC/MS-TOF) profile and antioxidant capacity on different in vitro and ex vivo systems.

\section{Materials and Methods}

\subsection{Chemicals and Reagents}

Reagents were purchased from various suppliers as follows: authentic standards of rutin, isoquercitrin, isorhamnetin, isorhanmetin 3-O-glucoside, narcissin, kaempferol (Extrasynthèse, Genay, France); FCR (Folin-Ciocalteu's reagent), gallic acid, $p$-hydroxybenzoic acid, sodium carbonate, sodium hydroxide, 6-hydroxy-2,5,7,8-tetramethylchroman-2-carboxylic acid (Trolox), 2,2'-Azino-bis(3-ethylbenzothiazoline-6-sulfonic acid) diammonium salt (ABTS), 2,2'-Azobis (2-methylpropionamidine) dihydrochloride (AAPH), fluorescein sodium salt and $2^{\prime}, 7^{\prime}$-dichlorofluorescein diacetate (DCFH-DA), as well as acetonitrile (HPLC grade), ethanol, methanol, formic acid (Sigma-Aldrich, St. Louis, MO, USA). In all experiments, Milli-Q (Merck Millipore, Darmstadt, Germany) water was used.

\subsection{Plant Material and Extraction}

Opuntia ficus-indica cladodes were collected from plants producing purple fruits ('Rossa' variety),

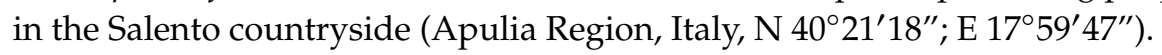

Cladodes were collected from the same plants at two developmental stages: immature (from spring shoots, fully developed cladodes at 3 weeks of development) and mature (from fall shoots, old cladodes at around 24 weeks).

Cladodes were cleaned from spines and glochids, cut in small pieces, processed in a Waring blender with liquid nitrogen, freeze-dried using a Freezone ${ }^{\circledR} 2.5$ model 76530 lyophilizer (Labconco Corp., Kansas City, MO, USA) for $48 \mathrm{~h}$ and stored at $-20^{\circ} \mathrm{C}$. This product was defined as the dry weight (DW) of cladode. Extraction was done in triplicate from $500 \mathrm{mg}$ (DW) macerated with $25 \mathrm{~mL}$ aqueous methanol $(80 \%)$ overnight at $4{ }^{\circ} \mathrm{C}$. After centrifugation $(4000 \times g)$, the supernatant was recovered and evaporated in vacuo at $32^{\circ} \mathrm{C}$ using a R-205 Büchi rotavapor (Büchi Labortechnik AG, Essen, Germany), 
then re-suspended in distilled water to a concentration of $50 \mathrm{mg} / \mathrm{mL}$. Extracts were then filtered on a $0.45-\mu \mathrm{m}$ CA syringe filter (Filtres Fioroni, Ingré, France) and portioned in 1-mL aliquot, stored at $-20{ }^{\circ} \mathrm{C}$ until analysis.

\subsection{Identification and Quantification of Phenolic Compounds}

The identification and quantification of phenolic compounds in cladode extracts was performed in triplicate (an analysis for each of the three extractions/replicas) using an Agilent 1200 Liquid Chromatography system (Agilent Technologies, Palo Alto, CA, USA) and the chromatographic conditions and column were the same already reported by Sabella et al. [13]. The identification of phenolic compounds was confirmed by a TOF LC/MS system (Agilent 6320, Agilent Technologies, Palo Alto, CA, USA), equipped with a dual ESI interface operating in negative ion mode [13].

The identified phenolic compounds were quantified by the external standard method using a six-point calibration curve of $p$-hydroxybenzoic acid $(0.5-100 \mathrm{mg} / \mathrm{L})$, rutin $(0.5-50 \mathrm{mg} / \mathrm{L})$, isorhamnetin $(0.5-50 \mathrm{mg} / \mathrm{L})$, and narcissin $(0.5-50 \mathrm{mg} / \mathrm{L})$.

\subsection{In Vitro Antioxidant Activity}

The Folin-Ciocalteu reducing capacity assay, the antioxidant activity by Oxygen Radical Absorbance Capacity (ORAC) and Trolox equivalent antioxidant capacity (TEAC) were evaluated in cladode extracts, as described in [14]. A rapid microplate methodology, using a microplate reader (Victor $^{\mathrm{TM}}$ X3, Perkin Elmer, Waltham, MA, USA) and 96-well plates (Costar, 96-well black round bottom plate, Corning) were used. All experiments were performed in triplicate, and two independent assays were performed for each sample.

\subsection{Ex Vivo Antioxidant Activity}

\subsubsection{Cellular Antioxidant Activity (CAA-RBC) Assay in Red Blood Cells}

The antioxidant activity of Opuntia cladode extracts was evaluated in an ex vivo erythrocytes system as described in Frassinetti et al. [15] as well as erythrocytes preparation. Trolox was used as a standard and the fluorescence was read at $485 \mathrm{~nm}$ excitation and $535 \mathrm{~nm}$ emission by using a Victor ${ }^{\mathrm{TM}}$ X3 microplate reader. Human erythrocytes from random subjects were exposed to a peroxyl radical generator, the AAPH, following one hour pre-treatment with 500 and $1000 \mu \mathrm{g} / \mathrm{mL}$ of cladode extracts. Each value was express according to the formula:

$$
\text { CAA unit }=100-\left(\int \mathrm{SA} \int \mathrm{CA}\right) \times 100
$$

where $\int_{\mathrm{SA}}$ is the integrated area of the sample curve and $\int_{\mathrm{CA}}$ is the integrated area of the control curve [16].

\subsubsection{Erythrocytes Oxidative Hemolysis}

Hemolysis of human erythrocytes was induced by thermal decomposition of AAPH as previously described [15]. Briefly, erythrocytes were incubated with Trolox $500 \mu \mathrm{M}$ (antioxidant standard) and cladode extracts at $37^{\circ} \mathrm{C}$ for $1 \mathrm{~h}$, followed by incubation with $50 \mathrm{mM}$ AAPH at $37{ }^{\circ} \mathrm{C}$ for $4 \mathrm{~h}$. The erythrocytes hemolysis was evaluated by spectrophotometric reading $(\lambda=540 \mathrm{~nm})$ of the hemoglobin released in the supernatant, and expressed as percentage compared to the control (AAPH-treated erythrocytes). 


\subsection{Antimicrobial Activity}

\subsubsection{Bacterial Media}

Nutrient Broth (NB), Nutrient Agar (NA), Mueller Hinton Broth (MHB), Mueller Hinton Agar (MHA), Mc Farland standard 0.5, Tripticase Soy Broth (TSB), were purchased from Oxoid (Basingstone, UK).

\subsubsection{Bacterial Strains and Growth Conditions}

The pathogenic bacterial strains were obtained from the American Type Culture Collection (ATCC). Gram-negative bacteria [Escherichia coli (ATCC 25922), Salmonella enterica ser. Typhimurium (ATCC 14028), and Enterobacter aerogenes (ATCC 13048)], and Gram-positive bacteria [Enterococcus faecalis (ATCC 29212) and Staphylococcus aureus (ATCC 25923)] were employed to test the antimicrobial activities of cladode extracts. All bacteria strains were grown on NB and MHB and incubated overnight at $37^{\circ} \mathrm{C}$ under aerobic conditions.

\subsubsection{Inhibition Assay-MINIMUM Inhibitory Concentration (MIC)}

The minimal inhibitory concentration (MIC) against selected bacteria was determined according to [7] with some modifications. Cladode extracts were diluted in sterile water to the concentration of $2000 \mu \mathrm{g} / \mathrm{mL}$; then, further dilutions were made up to the concentration of $50 \mu \mathrm{g} / \mathrm{mL}$.

Tested pathogenic microorganisms were cultured in $\mathrm{MHB}$ at $37^{\circ} \mathrm{C}$ for $16 \mathrm{~h}$. Initially, the cultures were diluted to match the turbidity of $0.5 \mathrm{McFarland}$ standard; thereafter, further dilutions with sterile MHB made it possible to obtain a suspension of about $1-5 \times 10^{5} \mathrm{CFU} / \mathrm{mL}$. Aliquot of bacterial suspensions $(50 \mu \mathrm{L})$ were added to a sterile 96-well plate containing $100 \mu \mathrm{L}$ of $\mathrm{MHB}$ and $100 \mu \mathrm{L}$ of cladode extract dilutions. A positive control (without cladode extract) was included on each microplate.

The plates were incubated in aerobic conditions at $37{ }^{\circ} \mathrm{C}$ for $24 \mathrm{~h}$. A microplate reader (Eti-System Fast Reader Sorin Biomedica, Modena, Italy) was used to record the optical density (OD) at $600 \mathrm{~nm}$. The MIC was defined as the lowest concentration of cladode extract able to inhibit the microorganism's growth.

\subsection{Biofilm Production and Inhibition Assay}

The biofilm production was determined using the method described by [2] with some modifications. The assay was performed using two Staphylococcus strains: the biofilm producer Staphylococcus aureus (ATCC 35556) and Staphylococcus epidermidis (ATCC 12228), used as a negative control, since it does not produce biofilm.

The strains were activated by culturing in $5 \mathrm{~mL}$ of TSB at $37^{\circ} \mathrm{C}$ for $24 \mathrm{~h}$. After $24 \mathrm{~h}$, the optical density (OD) was measured at $600 \mathrm{~nm}$ and appropriate dilutions were made in TSB $+1 \%$ sucrose, to obtain an optical density of 0.1 corresponding to about $10^{6}$ cells $/ \mathrm{mL}$. The assay was performed in sterile 96-well polystyrene plate (Greiner Bio-One Gmbh, Austria). Briefly, $100 \mu \mathrm{L}$ Staphylococcus aureus cells were inoculated and cultured with or without $100 \mu \mathrm{L}$ of cladodes extract (at concentrations ranging from 50 to $1500 \mu \mathrm{g} / \mathrm{mL}$ ), without shaking at $37^{\circ} \mathrm{C}$. After $24 \mathrm{~h}$ incubation, non-adherent cells were removed by dipping each sample three times in sterile PBS. Samples were fixed at $60^{\circ} \mathrm{C}$ for $1 \mathrm{~h}$ and the biofilms were stained with $0.1 \%$ solution of crystal violet in water, according to [17]. After staining, samples were washed thrice with distilled water. The quantitative analysis of biofilm production was performed by adding $125 \mu \mathrm{L}$ of $30 \%$ acetic acid to de-stain the samples. Afterwards, the OD at $492 \mathrm{~nm}$ was detected using the microplate reader. The percentage of biofilm inhibition was determined by the formula:

$$
\text { Biofilm reduction } \%=\frac{O D \text { control }- \text { OD sample }}{O D \text { control }} \times 100 \%
$$




\subsection{Statistical Analysis}

Statistical analysis has been carried out using GraphPad Prism, version 6.00 for Windows (GraphPad software, San Diego, CA, USA). Results were expressed as mean values \pm standard deviation (SD) of analysis of data deriving from extractions and assays made in triplicate. Differences between samples were analyzed by one-way analysis of variance (ANOVA) with Bonferroni's multiple comparison test; $p$-value lower than 0.05 was considered statistically significant.

\section{Results and Discussion}

\subsection{Polyphenolic Composition of Opuntia ficus-indica Cladode Extracts}

The polyphenolic extracts from immature and mature cladodes revealed a predominant presence of piscidic and eucomic acids. These phenolic acids were identified upon their retention time, UV-Visible spectra and fragmentation pattern; also their mass spectral characteristics (by TOF LC/MS) were compared with the available literature [18,19] (Figure 1).

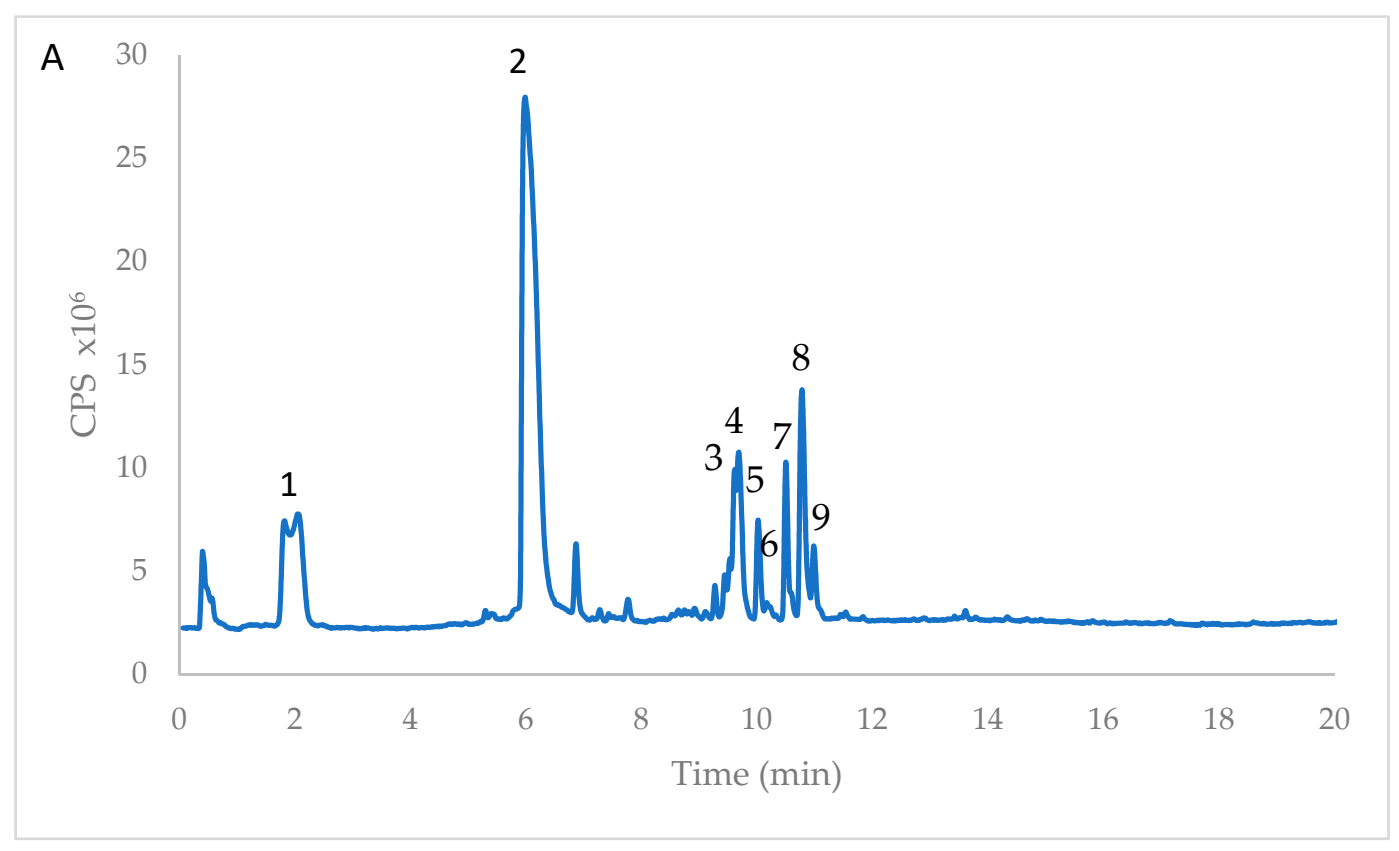

Figure 1. High performance liquid chromatography time-of-flight mass spectrometry (HPLC/MS-TOF) chromatogram of Opuntia ficus-indica extract from immature cladodes (imm). The chromatographic profile of mature cladode $(m)$ extract was similar, except for isorhamnetin glucoside (peak 9), only present in imm. The numbers indicating peaks refer to the identified compounds reported in Table 1.

The presence of piscidic acid and eucomic acid in Opuntia cladode has been reported [18,20]; others reported the occurrence of hydroxybenzoic acids derivatives (2- or 4- or 3,4-dihydroxy benzoic acids) [21].

In the mature cladodes, we found a higher content of both piscidic and eucomic acids in respect to the value reported (on a similar development stage) by [18], threefold and tenfold, respectively (Table 2). 
Table 1. Identification of phenolic acids and flavonols in Opuntia ficus-indica extracts (from imm and $m$ ) by means of High performance liquid chromatography time-of-flight mass spectrometry HPLC/TOF $(\mathrm{M}-\mathrm{H})^{-}$.

\begin{tabular}{ccccccccc}
\hline Peak & $\mathbf{R T}$ & $\begin{array}{c}\text { Formula } \\
{[\mathbf{M}-\mathbf{H}]^{-}}\end{array}$ & $\mathbf{m} / \mathbf{z}$ Exp & $\mathbf{m} / \mathbf{z}$ Calc & $\Delta$ (ppm) & Compound Name & Reference \\
\hline $\mathbf{1}$ & 1.988 & $\mathrm{C}_{11} \mathrm{H}_{11} \mathrm{O}_{7}$ & 255.0512 & 255.0510 & -0.67 & Piscidic acid & $\begin{array}{c}\text { Ginestra et al., } \\
\text { 2009 [18] }\end{array}$ \\
\hline $\mathbf{2}$ & 6.170 & $\mathrm{C}_{11} \mathrm{H}_{11} \mathrm{O}_{6}$ & 239.0567 & 239.0561 & -2.52 & Eucomic acid & $\begin{array}{c}\text { Ginestra et al., } \\
\text { 2009 [18] }\end{array}$ \\
\hline $\mathbf{3}$ & 9.628 & $\mathrm{C}_{34} \mathrm{H}_{41} \mathrm{O}_{20}$ & 769.6770 & 769.6773 & -0.39 & $\begin{array}{c}\text { Isorhamnetin } \\
\text { rhamnosyl rutinoside }\end{array}$ & $\begin{array}{c}\text { Santos-Zea et al., } \\
\text { 2011 [19] }\end{array}$ \\
\hline $\mathbf{5}$ & 10.022 & $\mathrm{C}_{27} \mathrm{H}_{29} \mathrm{O}_{16}$ & 609.1459 & 609.1461 & 0.34 & $\begin{array}{c}\text { Isorhamnetin glucosyl } \\
\text { rhamnosyl pentoside }\end{array}$ & $\begin{array}{c}\text { Santos-Zea et al., } \\
\text { 2011 [19] }\end{array}$ \\
\hline $\mathbf{6}$ & 10.034 & $\mathrm{C}_{27} \mathrm{H}_{29} \mathrm{O}_{16}$ & 609,1470 & 609,1461 & -1.43 & $\begin{array}{c}\text { Isorhamnetin } \\
\text { sambubioside }\end{array}$ & $\begin{array}{c}\text { Santos-Zea et al., } \\
\text { 2011 [19] }\end{array}$ \\
\hline $\mathbf{7}$ & 10.503 & $\mathrm{C}_{27} \mathrm{H}_{29} \mathrm{O}_{15}$ & 593.1517 & 593.1512 & -0.88 & $\begin{array}{c}\text { Kampherol glucosyl } \\
\text { rhamnoside }\end{array}$ & $\begin{array}{c}\text { Santos-Zea et al., } \\
2011[19]\end{array}$ \\
\hline $\mathbf{8}$ & 10.785 & $\mathrm{C}_{28} \mathrm{H}_{31} \mathrm{O}_{16}$ & 623.1645 & 623.1618 & -4.37 & $\begin{array}{c}\text { Narcissin } \\
\text { (isorhamnetin } \\
\text { rutinoside) }\end{array}$ & $\begin{array}{c}\text { Santos-Zea et al., } \\
\text { 2011 [19] }\end{array}$ \\
\hline
\end{tabular}

Table 2. Phenolic acids and flavonols content of Opuntia ficus-indica extracts, from immature and mature cladodes. Phenolic acids were quantified using the calibration curve of $p$-hydroxybenzoic acid. Flavonols were determined using calibration curves with the closest appropriate standard (rutin, isorhamnetin glucoside or isorhamnetin rutinoside). Mean values $(n=3) \pm$ standard deviation (SD) are expressed as dry weight (DW) or fresh weight (FW). The same letters $(a-h)$ in the column indicate that mean values are not significantly different $(p<0.05)$.

\begin{tabular}{|c|c|c|}
\hline Immature Stage & $\mathrm{mg} / \mathrm{g}$ DW & $\mathrm{mg} / \mathbf{1 0 0 g} \mathrm{FW}$ \\
\hline (1) Piscidic acid & $1.984 \pm 0.019 c$ & $14.681 \pm 0.146 c$ \\
\hline (2) Eucomic acid & $13.506 \pm 0.143 a$ & $99.944 \pm 1.062 a$ \\
\hline (4) Isorhamnetin rhamnosyl rutinoside & $0.411 \pm 0.003 d$ & $3.041 \pm 0.027 e$ \\
\hline (5) Isorhamnetin glucosyl rhamnosyl pentoside & $0.296 \pm 0.004 e$ & $2.192 \pm 0.033 d$ \\
\hline (6) Rutin & $2.030 \pm 0.023 c$ & $15.022 \pm 0.171 c$ \\
\hline (8) Narcissin (isorhamnetin rutinoside) & $3.188 \pm 0.042 b$ & $23.598 \pm 0.302 b$ \\
\hline (9) Isorhamnetin glucoside & $0.465 \pm 0.021 d$ & $3.444 \pm 0.161 e$ \\
\hline Mature Stage & $\mathrm{mg} / \mathrm{g}$ DW & $\mathrm{mg} / \mathbf{1 0 0 g} \mathrm{FW}$ \\
\hline (1) Piscidic acid & $3.281 \pm 0.032 b$ & $28.257 \pm 0.279 b$ \\
\hline (2) Eucomic acid & $1.616 \pm 0.02 f$ & $13.917 \pm 0.174 f$ \\
\hline (4) Isorhamnetin rhamnosyl rutinoside & $0.187 \pm 0.012 e$ & $1.618 \pm 0.104 d$ \\
\hline (5) Isorhamnetin glucosyl rhamnosyl pentoside & $0.266 \pm 0.007 e$ & $2.293 \pm 0.067 d$ \\
\hline (6) Rutin & $0.752 \pm 0.004 g$ & $6.474 \pm 0.034 g$ \\
\hline (8) Narcissin (isorhamnetin rutinoside) & $1.160 \pm 0.029 f$ & $9.985 \pm 0.25 h$ \\
\hline (9) Isorhamnetin glucoside & ND & ND \\
\hline
\end{tabular}


In the immature cladodes, we found a much higher value, as sum of piscidic and eucomic acids, even if the ratio is inverted: in immature cladode the predominant form is eucomic acid, instead in mature cladode piscidic acid is predominant (Table 2). Anyway, the amount of piscidic and eucomic acids found in O. ficus-indica cladode, particularly at immature stage, is exceptionally high.

Flavonol compounds (mainly isorhamnetin derivatives and rutin) were also identified (Figure 1 and Table 1). Isorhamnetin derivatives and rutin have been already described to be present in cladode extracts of different Opuntia species [18-23]. In those papers, isorhamnetin was reported as predominant core aglycone for flavonoids present in Opuntia sp., with low occurrence of quercetin and kaempferol. We confirmed these findings (Figure 1 and Table 2).

The content of isorhamnetin glucoside in our immature sample was similar to that one reported by Guevara-Figueroa and co-workers [21], in a wild variety (Amarillo) of Opuntia ficus-indica, instead our reported content of narcissin was much higher, as well as the rutin content (Table 2). In a mature cladode sample, the content of isorhamnetin derivatives (totaling $1.76 \mathrm{mg} / \mathrm{g} \mathrm{DW}$ ) was similar to that one reported in the above study $(1.69 \mathrm{mg} / \mathrm{g}$ DW) [21]. The total flavonols content in our immature samples $(6.78 \mathrm{mg} / \mathrm{g} \mathrm{DW})$ was in agreement with the content $(8.82 \mathrm{mg} / \mathrm{g} \mathrm{DW})$ reported in young cladodes of Opuntia ficus-indica [23]. In mature sample, the total flavonols content (totalling $2.51 \mathrm{mg} / \mathrm{g} \mathrm{DW}$ ) was again in agreement with [21] who found $\sim 3.5 \mathrm{mg} / \mathrm{g}$ DW.

Isorhamnetin derivatives, piscidic and eucomic acids present in such a high amount in cladode of Opuntia ficus-indica indicate that nopal can be considered a promising plant for the development of polyphenol-based commercial products. The effect of these phenolic compounds has been evaluated in vitro for contrasting hypercholesterolemia [24], and against UVA-induced oxidative stress on human keratinocytes [25], suggesting a possible pharmaceutical use of cladode extracts.

\subsection{In Vitro Antioxidant Activity}

Cladode extracts analysis revealed a much higher total phenol content, as well as antioxidant capacity, at immature stage of development, than mature cladode (Table 3). Therefore, the habit of Mexican population to eat 'nopalitos' (that is young prickly pads of 3-4 weeks of age) relays on a scientific basis of higher health benefit.

Table 3. Total phenols and antioxidant capacity, expressed as Oxygen Radical Absorbance Capacity (ORAC) and Trolox equivalent antioxidant capacity (TEAC), of Opuntia ficus-indica extracts, from immature and mature cladodes. Total phenols are expressed as gallic acid equivalents (GAE), TEAC and ORAC assays are expressed as Trolox Equivalent (TE). Mean values $(n=11) \pm$ standard deviation (SD) are expressed on a dry weight (DW) or fresh weight (FW) basis. The same letters $(a, b)$ in the same column indicate that mean values are not significantly different $(p<0.05)$.

\begin{tabular}{|c|c|c|c|c|c|c|}
\hline & \multicolumn{2}{|c|}{ Total Phenols } & \multicolumn{2}{|c|}{ TEAC } & \multicolumn{2}{|c|}{ ORAC } \\
\hline & $\begin{array}{c}\text { mg GAE/g } \\
\text { DW }\end{array}$ & $\begin{array}{c}\text { mg GAE/100 g } \\
\text { FW }\end{array}$ & $\begin{array}{c}\mu \mathrm{mol} \mathrm{TE} / \mathrm{g} \\
\text { DW }\end{array}$ & $\begin{array}{c}\mu \mathrm{mol} \\
\text { TE/100 g FW }\end{array}$ & $\begin{array}{c}\mathrm{mmol} \mathrm{TE} / \mathrm{g} \\
\mathrm{DW}\end{array}$ & $\begin{array}{c}\text { mmol } \\
\text { TE/100 g FW }\end{array}$ \\
\hline Immature stage & $54.02 \pm 1.62 a$ & $399.61 \pm 11.98 a$ & $12.55 \pm 1.14 a$ & $92.87 \pm 8.51 a$ & $0.88 \pm 0.08 a$ & $6.52 \pm 0.56 a$ \\
\hline Mature stage & $18.63 \pm 0.94 b$ & $160.14 \pm 8.09 b$ & $8.23 \pm 0.72 b$ & $70.85 \pm 6.22 b$ & $0.29 \pm 0.04 b$ & $2.47 \pm 0.36 b$ \\
\hline
\end{tabular}

Total phenol content (Table 3) was higher than that one reported in some studies [21,26] but in agreement with [23] (for immature cladode), and similar to that one reported in mature cactus pads from Tenerife [27] (for mature cladode); in fact, the phenol level results higher in immature cladodes if compared with mature, e.g., about $4 \mathrm{~g} / \mathrm{kg}$ in our immature cladode samples from Apulia, and $2.6 \mathrm{~g} / \mathrm{kg}$ in mature cladodes as reported by Rocchetti et al. for Sicilian Opuntia ficus-indica [26].

The antioxidant capacity measured by ABTS assay resulted higher for immature cladode than mature (12.5 vs $8.2 \mu \mathrm{mol} \mathrm{TE} / \mathrm{g}$ DW, respectively) (Table 3). Only one study dealt with TEAC of cladode extracts reporting a several-fold higher value [28]. The ORAC values for our immature and mature cladode (Table 3) agreed with the literature: $~ 770 \mu \mathrm{mol} \mathrm{TE} / \mathrm{g}$ DW [28]; a range from 260-380 $\mu \mathrm{mol}$ TE/g 
DW, in young pads [19]; $657 \mu \mathrm{mol}$ TE/g DW [29]. The ORAC value for immature cladode extracts was comparable to the value reported for blueberry; instead, that one for mature cladode was comparable to strawberry/raspberry values [30].

Therefore, from the experiments assessing the antioxidant capacity of cladodes extracts, we can conclude that both immature and mature cladodes are a good source of antioxidant functional compounds.

\subsection{Ex Vivo Antioxidant Activity}

\subsubsection{Cellular Antioxidant Activity Assay in Red Blood Cells (CAA-RBC)}

As shown in Figure 2A, cladodes pre-treated erythrocytes exhibited a significantly higher cellular antioxidant activity (CAA unit $=30 \pm 1$ ) compared to untreated cells (control, CAA $=0 ; p<0.01$ ), but lower than Trolox (CAA unit $=45 \pm 0.79$ ) used as standard. The cellular antioxidant activity of mature and immature cladodes was similar for both samples (30 \pm 1 and $29 \pm 0.9$, respectively).

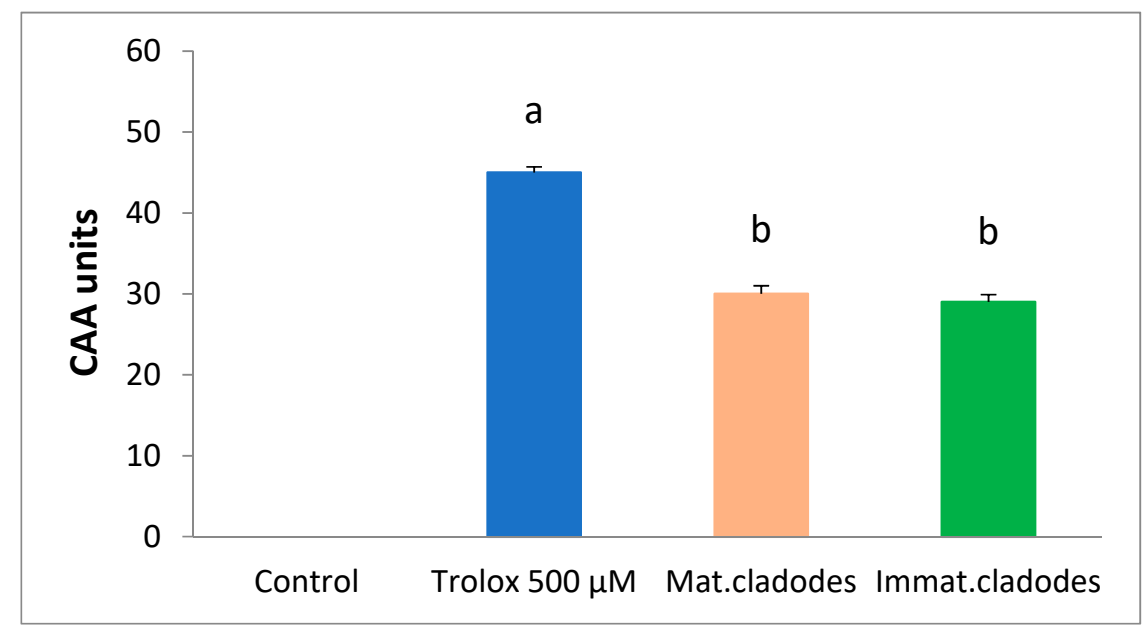

(A)

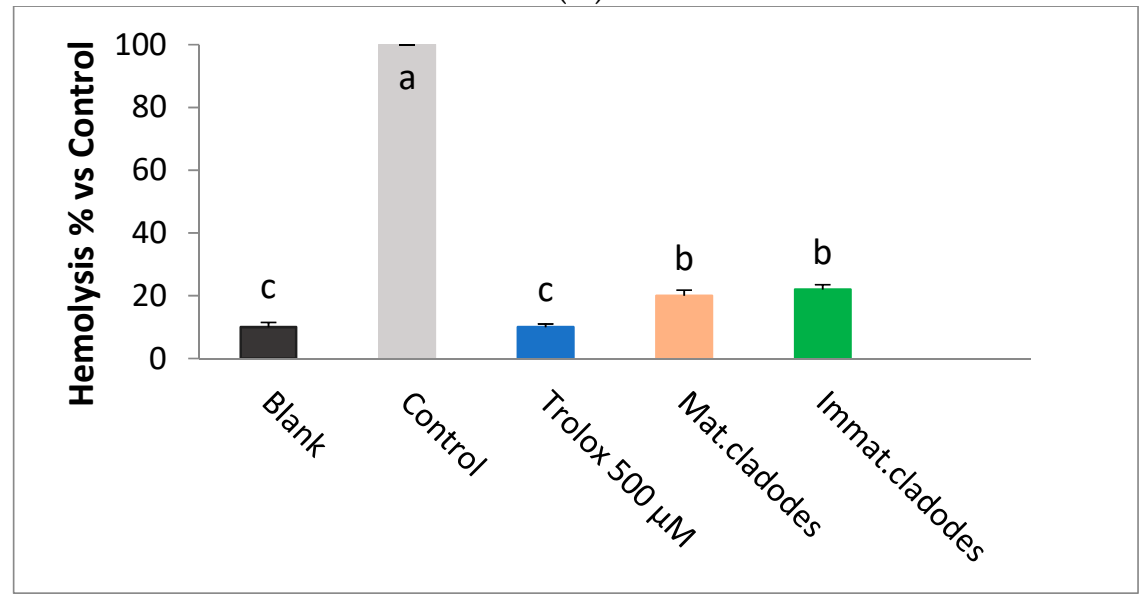

(B)

Figure 2. (A) Effects of Opuntia ficus-indica cladode extracts on the cellular antioxidant activity (CAA) in human erythrocytes. Trolox was used as reference standard. (B) Effects of Opuntia ficus-indica cladodes extracts on 2,2'-Azobis (2-methylpropionamidine) dihydrochloride (AAPH)-induced hemolysis in human erythrocytes. Trolox was used as reference standard. Assays were carried out in triplicate and the results were expressed as mean values \pm SD. Different letters indicate significant differences $(p \leq 0.05)$. One-way ANOVA with Bonferroni's multiple comparison test. 


\subsubsection{Haemolysis Assay}

Since erythrocyte is a unique cell model with simple metabolism and sensitivity to oxidation, oxidative haemolysis is widely used to evaluate antioxidant activity. Therefore, cladode extracts were tested on human erythrocytes to counteract the oxidative hemolysis induced by peroxyl radicals produced by AAPH thermal decomposition. The anti-hemolytic activity of cladode extracts was compared with that from erythrocytes exposed to AAPH alone (control). As shown in Figure 2B both Opuntia cladodes extracts exhibited a strong anti-hemolytic effect (about $80 \%$ ). This effect was statistically significant $(p \leq 0.001)$ compared to the control (that induced $100 \%$ of hemolysis) but lower than the Trolox (about 90\% hemolysis inhibition). No statistically significant differences were found between mature and immature cladodes anti-hemolytic effects.

\subsection{Antimicrobial Activity}

The antimicrobial activity against selected enteric bacterial strains was measured evaluating the O.D. at $600 \mathrm{~nm}$ in the presence of increasing doses of cladode extract. Different dilutions of methanol did not affect the bacterial growth (data not shown).

Gram-negative microorganisms (Escherichia coli ATCC 25922, Salmonella typhimurium ATCC 14028 and Enterobacter aerogenes ATCC 13048) were inhibited at a concentration of $2000 \mu \mathrm{g} / \mathrm{mL}$ of mature cladode extract, whereas immature cladode extract was more effective inhibiting at a concentration of $1500 \mu \mathrm{g} / \mathrm{mL}$ (Table 4). The two Gram-positive bacteria (Staphylococcus. aureus ATCC 25923 and Enterococcus. faecalis ATCC 29212) showed MIC values of $1500 \mu \mathrm{g} / \mathrm{mL}$ for mature and 1000 for immature cladode extract (Table 4). The MIC against planktonic cells of the biofilm producer Staphylococcus aureus ATCC 35556 was 1000 and $700 \mu \mathrm{g} / \mathrm{mL}$ for mature and immature extracts, respectively (Table 4).

Table 4. Minimal inhibitory concentrations (MIC) of Opuntia ficus-indica mature ( $m$ ) and immature cladode extracts (imm) against selected bacterial strains.

\begin{tabular}{llcc}
\hline \multicolumn{1}{c}{ Strain } & & MIC $(m) \mu \mathrm{g} / \mathrm{mL}$ & MIC (imm) $\mu \mathrm{g} / \mathrm{mL}$ \\
\hline Escherichia coli & ATCC 25922 & 2000 & 1500 \\
\hline Salmonella typhimurium & ATCC 14028 & 2000 & 1500 \\
\hline Enterobacter aerogenes & ATCC 13048 & 2000 & 1500 \\
\hline Enterococcus faecalis & ATCC 29212 & 1500 & 1000 \\
\hline Staphylococcus aureus & ATCC 25923 & 1500 & 1000 \\
\hline Staphylococcus aureus & ATCC 35556 & 1000 & 700 \\
\hline
\end{tabular}

Our results agree with several other studies showing that the inhibitory effect of phenolic compounds from natural extracts are more effective to Gram-positive than Gram-negative bacteria [7]. The susceptibility of bacteria to drugs depends on the characteristics of the drug (hydrophobicity or hydrosolubility) and on the microbial membrane composition [31].

The antimicrobial activity of plant phenolics has been extensively investigated against many different microorganisms [6]. We previously reported the antimicrobial activity of bergamot whole-fruit powder against potentially pathogenic bacteria [32]. In general, phenolic compounds are involved in membrane damage, protein and cell wall binding and enzyme inactivation; they can act as pro-oxidants, leading to damage of DNA, lipids and other biological molecules [33].

Few authors have reported the antimicrobial activity of Opuntia ficus-indica. Ginestra and co-workers [18] reported that different phytochemical fractions of Opuntia ficus-indica did not show antimicrobial activity against the tested bacterial strains. On the other hand, it has been reported the antimicrobial activity of alcoholic and aqueous extracts of Opuntia cladodes against Vibrio cholerae and Proteus mirabilis [34]. Moreover, other authors [35] described the antimicrobial activity of Opuntia 
cladodes against Escherichia coli and Staphylococcus aureus, with a minimum bactericidal concentration (MBC) of $4 \mathrm{mg} / \mathrm{mL}$ and $1 \mathrm{mg} / \mathrm{mL}$, respectively.

The antimicrobial activity of Opuntia cladodes extracts may be related to its high content of polyphenols, especially isorhamnetin that has been already reported exerting antimicrobial activity [36].

\subsection{Biofilm Inhibition}

The effects of cladode extracts on biofilm formation by Staphylococcus aureus ATCC 35556, a strong biofilm producer, was also investigated.

As shown in Figure 3, both cladode extracts (mature and immature) at concentration of $500 \mu \mathrm{g} / \mathrm{mL}$ did not inhibited the biofilm formation. At $1000 \mu \mathrm{g} / \mathrm{mL}$, only the immature cladode extract inhibited significantly the biofilm formation with an inhibition rate of $80 \%$. At $1500 \mu \mathrm{g} / \mathrm{mL}$ concentration, both extracts significantly inhibited the biofilm formation, with an inhibition rate of $71 \%$ for the mature cladode and $85 \%$ for the immature cladode.

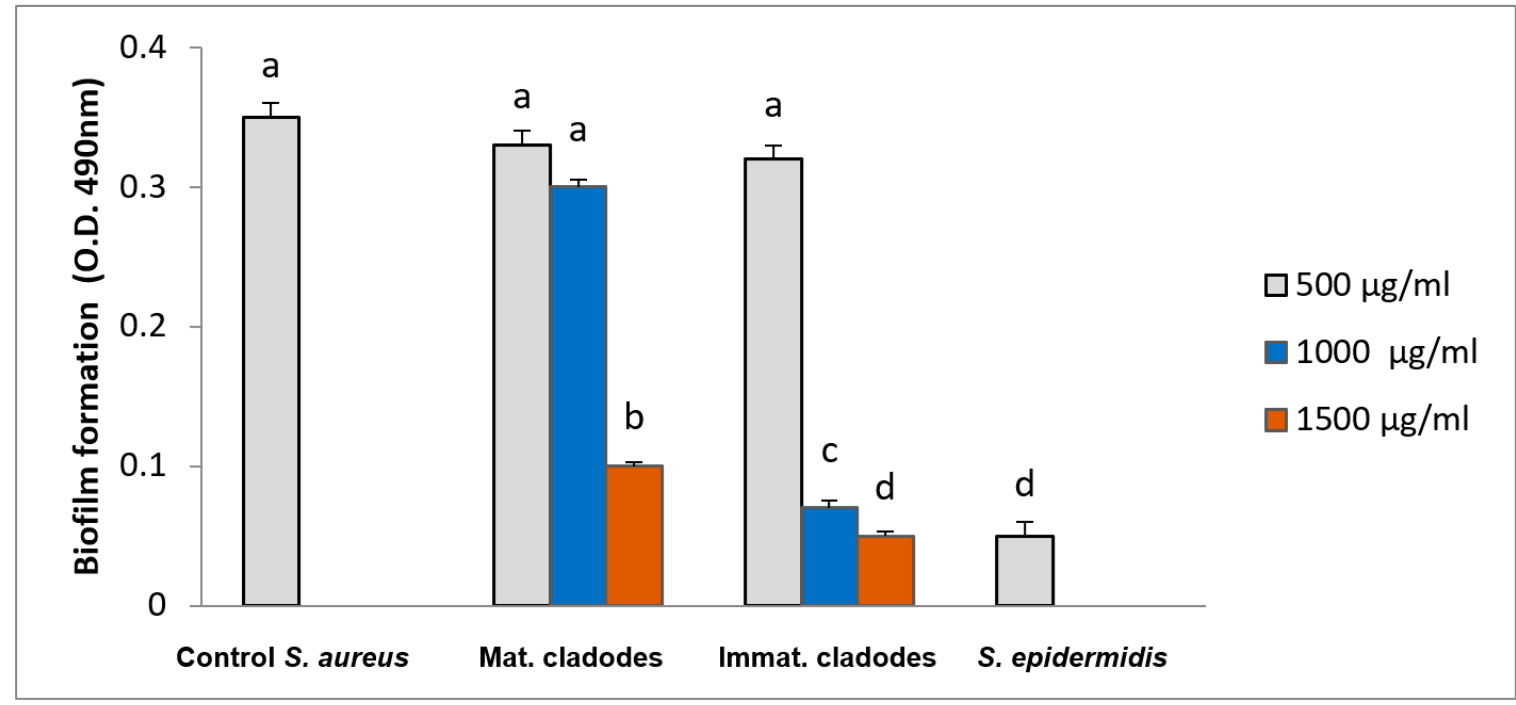

Figure 3. Effects of different concentrations of Opuntia ficus-indica cladode extracts on biofilm formation by Staphylococcus aureus ATCC 35556. Staphylococcus epidermidis ATCC 12228 was used as negative control. Assays were carried out in triplicate and the results were expressed as mean values \pm SD. Different letters indicate significant differences $(p \leq 0.05)$. One-way ANOVA with Bonferroni's multiple comparison test.

The inhibition of biofilm development at concentration of Opuntia cladode extracts higher than MIC demonstrated that the bacterial cells in a biofilm are more resistant to antimicrobial agents compared to the planktonic cells, which is a well-known feature. Our results concerning the inhibition of Staphylococcus aureus MRSA biofilm formation agree with previous works [10,37]. In our study, the inhibition of biofilm could be explained by the presence of flavonoids in cladodes extracts. In fact, flavonoids such as quercetin, apigenin, luteolin and rutin were found to be effective in the inhibition of Staphylococcus aureus biofilm [38,39].

\section{Conclusions}

The results obtained in this work indicate that cladodes of Opuntia ficus-indica are rich in phenolic compounds, particularly $p$-hydroxybenzoic acid derivatives, and possess in vitro antioxidant activity which results higher in the immature cladodes. The extracts exhibited in vivo antioxidant capacity with a strong anti-hemolytic effect. A selective inhibition against potentially pathogenic bacteria and a significant inhibition of the biofilm formation were shown by the cladodes at both developmental stages. To our knowledge, this is the first report on the characterization of Opuntia ficus-indica cladodes 
extracts for their antimicrobial and anti-biofilm properties. In conclusion, our results indicate that Opuntia ficus-indica cladode extracts, especially the immature ones, could be used for food purpose as functional food (being comparable to the antioxidant value of blueberries), as well as for food process control and food safety as recently proposed by Rocchetti et al. [26].

Author Contributions: Conceptualization, methodology, investigation, writing-original draft preparation: F.B. and S.F.; methodology, investigation, formal analysis: R.R., C.N.; writing-review and editing: L.D.B.

Funding: This research received no external funding

Conflicts of Interest: The authors declare no conflicts of interest.

\section{References}

1. Gyawali, R.; Hayek, S.A.; Ibrahim, S.A. Plant extracts as antimicrobials. In Handbook of Natural Antimicrobials for Food Safety and Quality; Taylor, T.M., Ed.; Elsevier: Cambridge, UK, 2015; pp. 31-47.

2. Di Ciccio, P.; Vergara, A.; Festino, A.R.; Paludi, D.; Zanardi, E.; Ghidini, S.; Ianieri, A. Biofilm formation by Staphilococcus aureus on food contact surfaces: Relationship with temperature and cell surface hydrophobicity. Food Control 2015, 50, 930-936. [CrossRef]

3. Stewart, P.S.; Costerton, J.W. Antibiotic resistance of bacteria in biofilms. Lancet 2001, 358, 135-138. [CrossRef]

4. Satpathy, S.; Sen, S.K.; Pattanaik, S.; Raut, S. Review on bacterial biofilm: An universal cause of contamination. Biocatal. Agric. Biotechnol. 2016, 7, 56-66. [CrossRef]

5. Doulgeraki, A.I.; Di Ciccio, P.; Ianieri, A.; Nychas, G.E. Methicillin-resistant food-related Staphylococcus aureus: A review of current knowledge and biofilm formation for future studies and applications. Res. Microbiol. 2017, 168, 1-15. [CrossRef]

6. Daglia, M. Polyphenols as antimicrobial agents. Curr. Opin. Biotechnol. 2012, 23, 174-181. [CrossRef] [PubMed]

7. Delgado Adámez, J.; Gamero Samino, E.; Valdés Sánchez, E.; González-Gómez, D. In vitro estimation of the antibacterial activity and antioxidant capacity of aqueous extracts from grape seeds (Vitis vinifera L.). Food Control 2012, 24, 136-141. [CrossRef]

8. Chibane, L.B.; Degraeve, P.; Ferhout, H.; Bouajila, J.; Oulahal, N. Plant antimicrobial polyphenols as potential natural food preservatives. J. Sci. Food Agric. 2018, 99, 1457-1474. [CrossRef] [PubMed]

9. Nostro, A.; Guerrini, A.; Marino, A.; Tacchini, M.; Di Giulio, M.; Grandini, A.; Saraçoğlu, H.T. In vitro activity of plant extracts against biofilm-producing food-related bacteria. Int. J. Food Microbiol. 2016, 238, 33-39. [CrossRef]

10. Brambilla, L.Z.S.; Endo, E.H.; Cortez, D.A.G.; Dias Filho, B.P. Anti-biofilm activity against Staphylococcus aureus MRSA and MSSA of neolignans and extract of Piper regnellii. Rev. Bras. Farmacognosia 2017, 27, 112-117. [CrossRef]

11. Stintzing, F.C.; Schieber, A.; Carle, R. Phytochemical and nutritional significance of cactus pear. Eur. Food Res. Technol. 2001, 212, 396-407. [CrossRef]

12. Hernández-Urbiola, M.I.; Pérez-Torrero, E.; Rodríguez-Garcia, M.E. Chemical analysis of nutritional content of prickly pads (Opuntia ficus-indica L.) at varied ages in an organic harvest. Int. J. Environ. Res. Public Health 2011, 8, 1287-1295.

13. Sabella, E.; Luvisi, A.; Aprile, A.; Negro, C.; Vergine, M.; Nicolì, F.; Miceli, A.; De Bellis, L. Xylella fastidiosa induces differential expression of lignification related-genes and lignin accumulation in tolerant olive trees cv. Leccino. J. Plant Physiol. 2018, 220, 60-68. [CrossRef]

14. Albano, C.; Negro, C.; Tommasi, N.; Gerardi, C.; Mita, G.; Miceli, A.; De Bellis, L.; Blando, F. Betalains, phenols and antioxidant capacity in cactus pear [Opuntia ficus-indica (L.) Mill.] fruits from Apulia (South Italy) genotypes. Antioxidants 2015, 4, 269-280. [CrossRef]

15. Frassinetti, S.; Gabriele, M.; Caltavuturo, L.; Longo, V.; Pucci, L. Antimutagenic and antioxidant activity of a selected lectin-free common bean (Phaseolus vulgaris L.) in two cell-based models. Plant Foods Hum. Nutr. 2015, 70, 35-41. [CrossRef] [PubMed]

16. Wolfe, K.L.; Liu, R.H. Cellular antioxidant activity (CAA) assay for assessing antioxidants, foods, and dietary supplements. J. Agric. Food Chem. 2007, 55, 8896-8907. [CrossRef] [PubMed]

17. O'Toole, G.A. Microtiter dish biofilm formation assay. J. Vis. Exp. 2011, 47. [CrossRef] 
18. Ginestra, G.; Parker, M.L.; Bennet, R.N.; Robertson, J.; Mandalari, G.; Narbad, A.; Lo Curto, R.B.; Bisignano, G.; Faulds, C.B.; Waldron, K.W. Anatomical, Chemical, and Biochemical Characterization of Cladodes from Prickly Pear [Opuntia ficus-indica (L.) Mill.]. J. Agric. Food Chem. 2009, 57, 10323-10330. [CrossRef]

19. Santos-Zea, L.; Guitiérrez-Uribe, J.A.; Serna-Saldivar, O. Comparative analysis of total phenols, antioxidant activity, and flavonol glycoside profile of cladode flours from different varieties of Opuntia spp. J. Agric. Food Chem. 2011, 59, 7054-7061. [CrossRef] [PubMed]

20. Di Lorenzo, F.; Silipo, A.; Molinaro, A.; Parrilli, M.; Schiraldi, C.; D'Agostino, A.; Izzo, E.; Rizza, L.; Bonina, A.; Bonina, F.; Lanzetta, R. The polysaccharide and low molecular weight components of Opuntia ficus indica cladodes: Structure and skin repairing properties. Carbohydr. Polym. 2017, 157, 128-136. [CrossRef]

21. Guevara-Figueroa, T.; Jiménez-Islas, H.; Reyes-Escogido, M.L.; Mortensen, A.G.; Laursen, B.B.; Lin, L.-W.; Barba de la Rosa, A.P. Proximate composition, phenolic acids, and flavonoids characterization of commercial and wild nopal (Opuntia spp.). J. Food Compos. Anal. 2010, 23, 525-532. [CrossRef]

22. Ressaissi, A.; Attia, N.; Falé, P.L.; Pacheco, R.; Teixeira, V.H.; Machuqueiro, M.; Borges, C.; Serralheiro, M.L.M. Aqueous extracts from nopal (Opuntia ficus-indica): Antiacetylcholinesterase and antioxidant activity from phenolic bioactive compounds. Int. J. Green Herb. Chem. 2016, 5, 337-348.

23. Medina-Torres, L.; Vernon-Carter, E.J.; Gallegos-Infante, J.A.; Rocha-Guzman, N.E.; Herrera-Valencia, E.E.; Calderas, F.; Jiménez-Alvarado, R. Study of the antioxidant properties of extracts obtained from nopal cactus (Opuntia ficus-indica L.) cladodes after convective drying. J. Sci. Food Agric. 2011, 91, 1001-1005. [CrossRef] [PubMed]

24. Ressaissi, A.; Attia, N.; Falé, P.L.; Pacheco, R.; Victor, B.L.; Machuqueiro, M.; Borges, C.; Serralheiro, M.L.M. Isorhamnetin derivatives and piscidic acid for hypercholesterolemia: Cholesterol permeability, HMG-CoA reductase inhibition, and docking studies. Arch. Pharmacal Res. 2017, 40, 1278-1286. [CrossRef]

25. Petruk, G.; Di Lorenzo, F.; Imbimbo, P.; Silipo, A.; Bonina, A.; Rizza, L.; Piccoli, R.; Monti, D.M.; Lanzetta, R. Protective effect of Opuntia ficus-indica L. cladodes against UVA-induced oxidative stress in normal human keratinocytes. Bioorg. Med. Chem. Lett. 2017, 27, 5485-5489. [CrossRef]

26. Rocchetti, G.; Pellizzoni, M.; Montesano, D.; Lucini, L. Italian Opuntia ficus-indica Cladodes as Rich Source of Bioactive Compounds with Health-Promoting Properties. Foods 2018, 7, 24. [CrossRef]

27. Pérez Méndez, L.; Tejera Flores, F.; Darias Martín, J.; Rodríguez Rodríguez, E.M.; Díaz Romero, C. Physicochemical characterization of cactus pads from Opuntia dillenii and Opuntia ficus indica. Food Chem. 2015, 188, 393-398. [CrossRef] [PubMed]

28. Corral-Aguayo, R.D.; Yahia, E.M.; Carrillo-Lopez, A.; González-Aguilar, G. Correlation between some nutritional components and the total antioxidant capacity measured with six different assays in eight horticultural crops. J. Agric. Food Chem. 2008, 56, 10498-10504. [CrossRef]

29. Avila-Nava, A.; Calderón-Oliver, M.; Medina-Campos, O.N.; Zou, T.; Gu, L.; Torres, N.; Pedraza-Chaverri, J. Extract of cactus (Opuntia ficus indica) cladodes scavenge reactive oxygen species in vitro and enhances plasma antioxidant capacity in humans. J. Funct. Foods 2014, 10, 13-24. [CrossRef]

30. Wu, X.; Beecher, G.R.; Holden, J.M.; Haytowitz, D.B.; Gebhardt, S.E.; Prior, R.L. Lipophilic and hydrophilic antioxidant capacities of common foods in the United States. J. Agric. Food Chem. 2004, 52, 4026-4037. [CrossRef] [PubMed]

31. de Almeida, C.G.; Garbois, G.D.; Amaral, L.M.; Diniz, C.C.; Le Hyaric, M. Relationship between structure and antibacterial activity of lipophilic N-acyldiamines. Biomed. Pharmacother. 2010, 64, 287-290. [CrossRef] [PubMed]

32. Gabriele, M.; Frassinetti, S.; Caltavuturo, L.; Montero, L.; Dinelli, G.; Longo, V.; Pucci, L. Citrus bergamia powder: Antioxidant, antimicrobial and anti-inflammatory properties. J. Funct. Foods 2017, 31, 255-265. [CrossRef]

33. Duda-Chodak, A.; Tarko, T.; Satora, P.; Sroka, P. Interaction of dietary compounds, especially polyphenols, with the intestinal microbiota: A review. Eur. J. Nutr. 2015, 54, 325-341. [CrossRef]

34. El-Mostafa, K.; El Karrassi, Y.; Badreddine, A.; Andreoletti, P.; Vamecq, J.; El Kebbai, M.S.; Latruffe, N.; Lizard, G.; Nasser, B.; Cherkaoui-Malki, M. Nopal cactus (Opuntia ficus-indica) as a source of bioactive compounds for nutrition, health and disease. Molecules 2014, 19, 14879-14901. [CrossRef] [PubMed]

35. Sánchez, E.; Rivas Morales, C.; Castillo, S.; Leos-Rivas, C.; García-Becerra, L.; Ortiz Martínez, D.M. Antibacterial and Antibiofilm Activity of Methanolic Plant Extracts against Nosocomial Microorganisms. Evid. Based Complement. Altern. Med. 2016, 2016, 1-8. [CrossRef] 
36. Bhattacharya, D.; Koley, H. Antibacterial activity of polyphenolic fraction of kombucha against enteric bacterial pathogens. Curr. Microbiol. 2016, 73, 885-896. [CrossRef]

37. Bazargani, M.; Rohloff, J. Antibiofilm activity of essential oils and plant extracts against Staphylococcus aureus and Escherichia coli biofilms. Food Control 2016, 61, 156-164. [CrossRef]

38. Slobodníková, L.; Fialová, S.; Rendeková, K.; Kováč, J.; \& Mučaji, P. Antibiofilm activity of plant polyphenols. Molecules 2016, 21, 1717. [CrossRef]

39. Al-Shabib, N.A.; Husain, F.M.; Ahmad, I.; Khan, M.S.; Khan, R.A.; Khan, J.M. Rutin inhibits mono and multi-species biofilm formation by foodborne drug resistant Escherichia coli and Staphylococcus aureus. Food Control 2017, 79, 325-332. [CrossRef]

(C) 2019 by the authors. Licensee MDPI, Basel, Switzerland. This article is an open access article distributed under the terms and conditions of the Creative Commons Attribution (CC BY) license (http://creativecommons.org/licenses/by/4.0/). 